\title{
FASILITAS KESEHATAN HOLISTIK DI KEBON JERUK, JAKARTA BARAT
}

\author{
Klarissa Febriana ${ }^{1)}$, Diah Anggraini ${ }^{2)}$ \\ 1) Program Studi S1 Arsitektur, Fakultas Teknik, Universitas Tarumanagara, rissa.syalala@hotmail.com \\ 2) Program Studi S1 Arsitektur, Fakultas, Teknik Universitas Tarumanagara, diaha@ft.untar.ac.id
}

\begin{abstract}
Abstrak
Generasi milenial sebagai generasi yang berada dalam usia produktif memiliki cara pandang serta sikap yang berbeda terhadap kesehatan seiring dengan perubahan tindakan kesehatan dari pengobatan penyakit ke pencegahan penyakit/pemeliharaan kesehatan. Mereka juga menganut prinsip kesehatan holistik dengan penekanan pada keseimbangan antara tubuh, jiwa dan pikiran. Selain itu, tingkat stres dan depresi yang tinggi di kalangan milenial menimbulkan keinginan untuk 'melarikan diri'/relaksasi sehingga fasilitas kesehatan holistik hadir sebagai wadah untuk memenuhi kebutuhan mereka akan kondisi kesehatan holistik serta mengusahakan pola hidup urban yang lebih sehat. Proyek terletak di Jalan Panjang, Kecamatan Kebon Jeruk, Jakarta Barat dengan dominasi kawasan perumahan menengah hingga atas dan perkantoran, aksesibilitas tinggi, serta posisi tapak pada lapisan pertama (sisi jalan kolektor primer) yang membuatnya lebih terekspos. Metode perancangan yang digunakan adalah metode bahasa pola dengan perancangan bangunan secara fungsional (berdasarkan kebutuhan) serta analisis lingkungan proyek secara makro, mezo, dan mikro. Fasilitas kesehatan holistik ini mengombinasikan program yang bersifat fisik serta mental/spiritual dalam rangka pencapaian kesehatan holistik dan mengarah kepada kesehatan general serta kesejahteraan (well-being). Proyek ini diharapkan dapat memberi dampak positif bagi lingkungannya dengan menjadikan gaya hidup sehat sebagai bagian dari kehidupan penduduk sekitar, meningkatkan produktivitas serta kualitas hidup. Selain itu, proyek juga diharapkan menjadi sarana pembentukan komunitas lingkungan yang baru dan sehat serta menjadi tempat pelarian yang memberi ketenangan/relaksasi dengan integrasi unsur alam dalam bangunannya.
\end{abstract}

Kata kunci: holistik; milenial; wadah

\begin{abstract}
Millennials as a generation entering the productive stage have different perspectives and attitude towards health as health action shifted from illness medication to illness prevention/health maintenance. They also embrace holistic health principle with an accent on balance between the body, mind, and soul. Furthermore, high stress and depression rate among millennials brings out their eagerness to 'runaway'/relax so holistic health amenities takes it's role as a vessel to fulfill their needs of holistic health as to attempt a healthier urban life. The project is located at Jalan Panjang, Kebon Jeruk, West Jakarta which is dominated by elite housing area and office complex, high accessibility, and the site located on first layer (edge of primary collector street) which makes it more exposed. The design method used in the design process is pattern language with functional design (depending on building users) and macro, mezzo, and micro environmental analysis. This holistic health amenities combines physical and mental/spiritual programs to reach holistic health and aims to general health and well-being. This project is expected to give positive outcome to its surrounding environment by making healthy lifestyle as a part of the residents' life, improving productivity and life quality. The project is also expected to be a place where new healthy communities form as to be a retreat place that gives serenity/relaxation with nature elements integrated into the building.
\end{abstract}

Keywords: holistic; millennials; vessel 


\section{PENDAHULUAN}

Jakarta sebagai ibu kota negara berkepadatan tinggi dihuni oleh masyarakat yang beragam, termasuk di dalamnya berbagai generasi, seperti generasi milenial (generasi $Y$ ) yang mendominasi dari segi jumlah (dibandingkan generasi $X$, generasi $Z$, serta Baby Boomers) dan sedang dalam masa produktif. Generasi milenial Jakarta, yang pada umumnya sedang menempuh pendidikan, bekerja maupun berkeluarga, menjalani kehidupan yang sibuk hingga menimbulkan tingkat stres dan depresi yang lebih tinggi dibandingkan generasi sebelumnya. Di sisi lain, sebagai generasi yang terintegrasi dengan teknologi (digitally native), mereka menghabiskan cukup banyak waktu menggunakan gawai sehingga kurang meluangkan waktu khusus untuk hal mendasar kehidupan yang juga penting seperti kesehatan.

Walaupun demikian, hal ini bukan berarti mereka tidak memberi perhatian terhadap kesehatan. Sebuah survei nasional oleh CSIS (Centre for Strategic and International Studies) mengindikasikan bahwa kegiatan yang paling menarik minat generasi milenial adalah olahraga, dan hal yang mereka anggap penting sebagai sumber kebahagiaan adalah kesehatan. Selain itu, sebuah riset oleh PT. Neurosensum Technology International terhadap generasi milenial Jabodetabek menunjukkan bahwa mereka meningkatkan pengeluarannya untuk spa, pijat, refleksiologi sebanyak 40\% (meningkat 1,4 kali lipat) dan 80\% (meningkat 2 kali lipat) dalam dua tahun terakhir untuk kelas kebugaran, keanggotaan gym, dan fasilitas olahraga lainnya.

Bagi generasi milenial, menjadi sehat bukan hanya sekadar tidak sakit, tetapi merupakan pencapaian secara aktif dalam kehidupan sehari-hari. Hal ini terlihat dalam perilaku mereka yang memilih makanan sehat, angka perokok yang lebih rendah dari generasi sebelumnya, dan penggunaan aplikasi-aplikasi digital untuk olahraga dan pencarian informasi online mengenai makanan/minuman sehat. Studi oleh Iconoculture Consumer Insights (2017) menunjukkan pemikiran generasi milenial bahwa kesehatan utuh merupakan gabungan kondisi fisik, mental, emosional, dan spiritual yang seimbang (spiritual dalam arti ketenangan pikiran dan batin).

Untuk mewadahi kebutuhan generasi milenial akan kesehatan secara fisik, mental, dan spiritual pada masa sekarang maupun mendatang serta mengusahakan pola hidup urban yang lebih sehat dan seimbang, proyek ini diusulkan. Kesehatan sebagai hal mendasar dalam hidup merupakan kondisi ideal yang diinginkan dan masyarakat khususnya kaum milenial mengusahakannya dengan tingkat frekuensi yang berbeda (sering maupun jarang). Kesadaran akan gaya hidup sehat yang mulai terbangun dan kian menjadi tren di kota Jakarta memberi peluang bagi program untuk turut mendukung pergeseran gaya hidup tersebut. Kesehatan dan kebugaran yang optimal dan seimbang akan berdampak baik dan meningkatkan produktivitas generasi milenial yang berusaha memenuhi kebutuhan mereka demi kesejahteraan.

\section{Visi Proyek}

Membantu masyarakat khususnya generasi milenial mencapai kondisi kesehatan/kebugaran yang seimbang dan holistik (fisik, mental, emosional, dan spiritual) untuk kehidupan yang lebih baik, tingkat produktivitas tinggi dan pencapaian kesejahteraan.

\section{Misi Proyek}

- Menyediakan sarana pelayanan untuk meningkatkan kualitas kesehatan holistik (fisik, mental, emosional, spiritual)

- Menyediakan area khusus makanan, minuman sehat dan area komunal

- Mengintegrasikan elemen alam ke dalam proyek

- Menyediakan area terbuka hijau yang cukup pada lahan proyek

- Menyediakan jalur-jalur yang nyaman bagi pesepeda dan pejalan kaki dengan lebar yang memenuhi standar serta kelengkapan unsur-unsur jalur pedestrian dan sepeda

\section{Sumbangan Proyek Bagi Kehidupan Kota}

Proyek diharapkan dapat mewadahi kebutuhan masyarakat, khususnya generasi milenial dalam mencapai kesehatan menyeluruh sehingga dapat meningkatkan kebahagiaan, produktivitas, dan kesejahteraan mereka. Proyek juga diharapkan dapat memberikan kontribusi terhadap kesehatan generasi milenial tidak hanya pada masa sekarang, namun juga 
masa mendatang karena usaha pencapaian kesehatan tidak terikat usia maupun jenis kelamin dan proses pencapaian kesehatan holistik merupakan proses yang berkelanjutan. Di samping itu, proyek juga diharapkan dapat membantu memperbaiki kualitas iklim mikro (lingkungan) dengan kehadiran ruang hijau serta membentuk komunitas masyarakat kota yang baru sehingga melahirkan kondisi kehidupan sosial kota yang lebih sehat.

\section{KAJIAN LITERATUR}

Tipe dan perilaku dalam arsitektur berelasi secara timbal balik. Menurut Quatremere de Quincy, tipe mewakili gagasan tentang elemen yang seharusnya berfungsi sebagai aturan untuk model (Agudin, 1995). Tipe terbagi ke dalam dua bentuk dasar, yaitu tipe berupa model (klasifikasi berdasarkan kemiripan morfologis) dan tipe berupa ide dari sebuah elemen yang memberikan aturan bagi bentukan model sebagai objek yang diulang (Lee dan Jacoby, 2011). Sedangkan tipologi merupakan ilmu yang mempelajari tentang tipe/konsep yang memilah kelompok objek berdasarkan kesamaan sifat-sifat dasar (D.K. Ching, 1979). Perilaku sendiri merupakan cara seseorang atau sesuatu bertindak terhadap subjek/objek lain di sekitarnya dan dapat digunakan untuk memahami korelasi antara kehidupan manusia, alam, dan lingkung bangun (Tsukamoto dan Kaijima, 2010).

Pada satu sisi perilaku menghasilkan tipe dimana tipe muncul sebagai pendukung perilaku manusia dan alam, kemudian pada saat tertentu tipe bergantian menghasilkan suatu perilaku baru karena tipe dapat mengatur dan memanipulasi perilaku manusia dan alam (Moneo, 1978). Arsitektur memang dibangun untuk memenuhi kebutuhan manusia, namun sebaliknya, dari arsitektur itulah muncul kebutuhan manusia yang baru kembali (Tandall dan Egam, 2011).

\section{Arsitektur dan Kesejamanan}

Generasi milenial (lahir pada kisaran tahun 1982 hingga 2000) yang memasuki usia produktif terintegrasi dengan teknologi (digitally native), berpikiran terbuka, dan saling terkoneksi (Howe dan Strauss, 1991). Mereka tidak memiliki keinginan tinggi untuk memiliki hal-hal bersifat materi, tetapi lebih mencari pengalaman, makanan/minuman, dan hal-hal berkaitan dengan kebugara (Yuswohady, 2018). Generasi ini meprioritaskan work-life balance (Twenge, 2010) dan senang mengunjungi tempat yang 'instagramable' (indah untuk difoto dan dibagikan di media sosial yang mereka gunakan).

Arsitektur sebagai hasil pemikiran proses rancang arsitektur memberikan tanda/makna sesuai zaman dan tempatnya berada sehingga bentuk dalam arsitektur selalu beradaptasi dengan lingkungan dan budaya di sekitarnya yang pada akhirnya mengidentifikasi fungsi (Broadbent, 1980). Perubahan pada generasi yang dominan mengakibatkan pergeseran cara berperilaku dan gaya hidup ke arah baru sehingga berujung pada perubahan arsitektur sebagai wujud adaptasi terhadap lingkungan (Broadbent, 1980).

\section{Kebugaran dan Kesehatan (Wellness)}

Wellness merupakan istilah modern dengan akar/sumber yang telah ada sejak zaman purbakala, seperti Ayurveda (sistem holistik yang menciptakan harmoni antara tubuh, pikiran, dan jiwa), pengobatan tradisional Cina (pendekatan holistik), Hippocrates (dokter Yunani pertama yang berfokus pada pencegahan penyakit), obat-obatan purbakala Roma (Global Wellness Institute, 2018). Pada tahun 1975, Dr. John Travis membuka wellness center pertama dan mengusulkan tiga kunci konsep wellness, yaitu:

- The Illness-Wellness Continuum (paradigma wellness menuju ke tingkat yang lebih tinggi) 


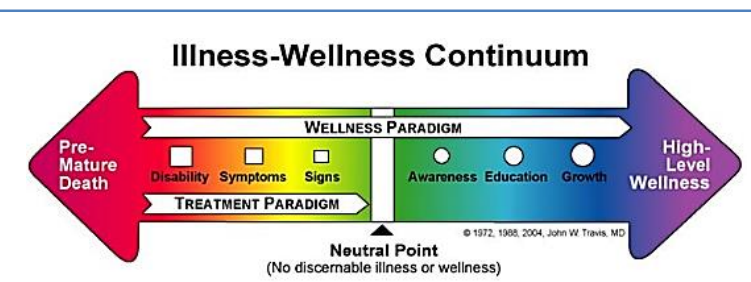

Gambar 1. Illness Wellness Continuum

Sumber: Travis, 1972

- The Iceberg Model of Health (penyakit dan kesehatan hanyalah ujung dari gunung es dan untuk memahami penyebabnya, bagian bawah permukaan perlu dilihat

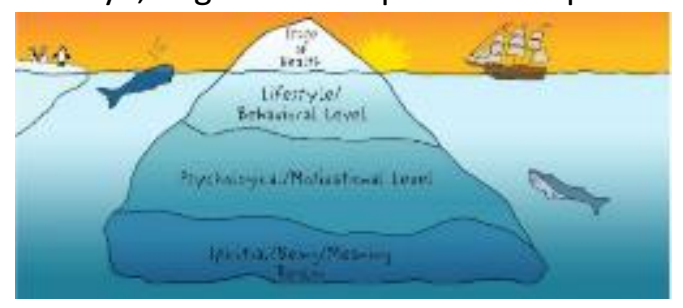

Gambar 2. The Iceberg Model of Health

Sumber: Travis, 1972

- The Wellness Energy System (energi yang masuk dan keluar dari manusia)

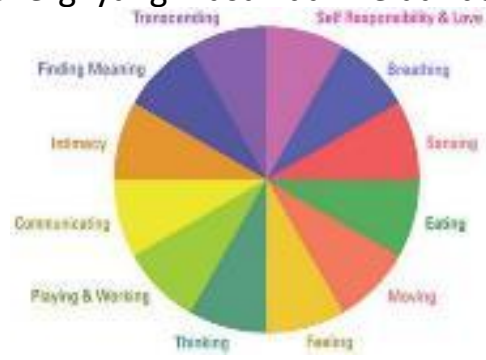

Gambar 3. 12 Dimensions of Wellness

Sumber: Travis, 1972

\section{Fasilitas Kesehatan Holistik, Persepsi Tentang Kesehatan dan Tren Kesehatan}

Fasilitas kesehatan holistik secara luas merupakan tempat yang menawarkan pelayanan kesehatan bagi tubuh, jiwa, dan pikiran. Secara garis besar terdapat tiga tipe fasilitas tersebut, yaitu fasilitas untuk kesehatan general dan kesejahteraan (well-being), fasilitas dengan pelayanan kesehatan dan kebugaran tertentu, serta fasilitas yang dijalankan oleh dokter (Athena Wellness Center, 2018). Manusia sebagai makhluk hidup terdiri atas unsur fisik dan psikologis. Oleh karenanya, mereka memiliki hasrat untuk memenuhi kedua kebutuhan tersebut dimana kekurangan salah satunya membuat manusia merasa tidak seimbang.

Tabel 1. Hal-hal yang diusahakan Manusia

\begin{tabular}{cc}
\hline Eksternal & Internal \\
\hline Keluarga & Meditasi \\
Teman & Refleksi diri \\
Karier & Pengaturan stres \\
Pendidikan & Psikoterapi \\
Status & Pertumbuhan pribadi \\
Kekayaan & Ikatan cinta kasih \\
Politik & Material spiritual \\
Kegemaran & Eksplorasi kebijaksanaan \\
\hline Sumber: Chopra
\end{tabular}

Sumber: Chopra, 2014 
Dalam kebutuhan psikologis, kegiatan leisure sangat penting dan dapat membantu pengembangan pribadi yang ditandai dengan kondisi internal yang meningkat dan kesadaran akan diri (self) yang lebih kuat (Cohen, 2013).

Saat ini konsepsi dunia holistik dan ekologis yang baru melihat manusia serta alam semesta sebagai sistem hidup dan kesehatan merupakan fenomena multidimensional yang melibatkan aspek fisik, psikologis, dan sosial (Capra, 1997). Generasi milenial mendukung konsepsi baru ini dan hal itu terlihat dari perilaku mereka yang memilih untuk melakukan aktivitas fisik serta mengubah apa yang mereka makan/minum dibandingkan dengan mengonsumsi obat-obatan (Nielsen Global Health \& Wellness, 2015). Mereka juga cenderung mencari pengobatan alternatif dan beberapa hal yang menarik minat mereka adalah pengobatan akupuntur, terapi, obat-obat natural, dan kegemaran memelihara ikan ataupun menanam tanaman (berdasarkan penelitian hal tersebut dapat meredakan detak jantung dan tekanan darah serta memperbaiki suasana hati).

\section{METODE}

Metode yang digunakan dalam perancangan fasilitas kesehatan holistik ini adalah metode pattern language/bahasa pola dari Christopher Alexander tahun 1979 (pembentukan ruang berdasarkan kebutuhan dan kenyamanan pengguna secara fungsional) serta analisis-analisis terhadap lingkungan tapak secara makro, mezo, dan mikro. Selain itu, tema konsep yang diangkat turut menjadi bagian dari proses merancang.

\section{Analisis Makro}

Jakarta Barat dinilai sebagai area pertumbuhan properti paling pesat (Indonesian Property Magazine, 2019) dengan jumlah penduduk generasi milenial tertinggi dibandingkan generasi lainnya serta didominasi oleh penduduk kelas menengah hingga atas. Berdasarkan peta zonasi kecamatan Jakarta Barat, Kecamatan Kebon Jeruk memiliki persentase kawasan perumahan (rumah sedang hingga besar) tertinggi (81.36\%) berdasarkan Laporan Tahunan Kecamatan Kebon Jeruk 2016, dan keberadaannya di sisi timur Kecamatan Kembangan (pusat pemerintahan Jakarta Barat) menjadikannya area yang strategis.

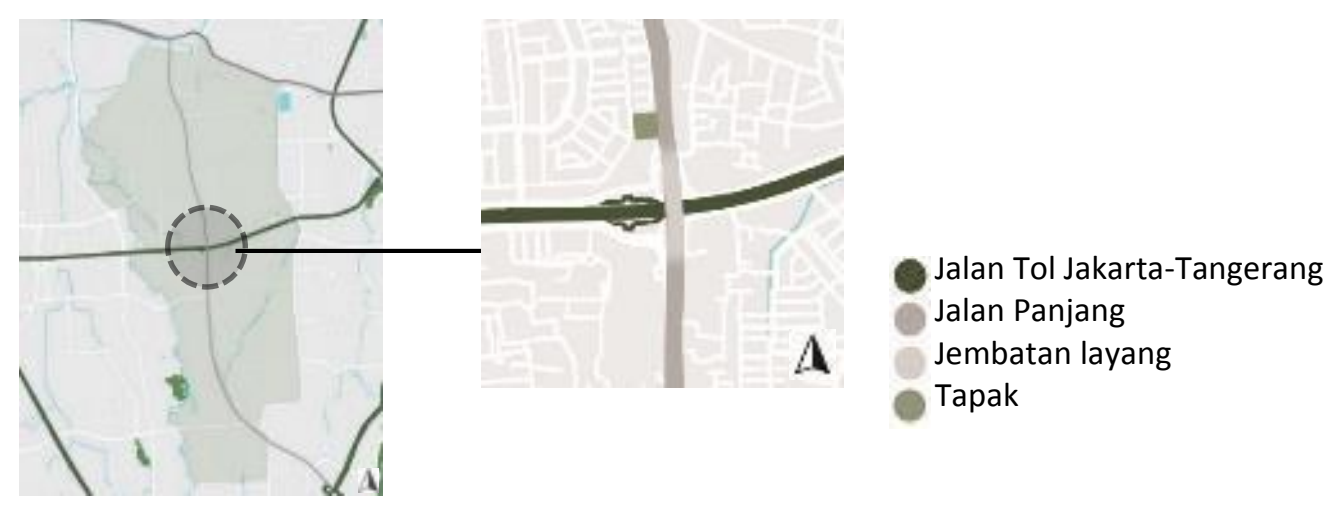

Gambar 4. Lokasi Tapak di Kecamatan Kebon Jeruk Sumber: Google, 2019 
Tapak berada pada sisi barat Jalan Panjang sehingga posisinya berada pada lapisan pertama (first layer) yang menjadikannya lebih terekspos. Tapak juga berada pada area simpul Kecamatan Kebon Jeruk yang merupakan persilangan Jalan Tol Jakarta-Tangerang dan Jalan Panjang dengan arus kendaraan yang cukup tinggi.
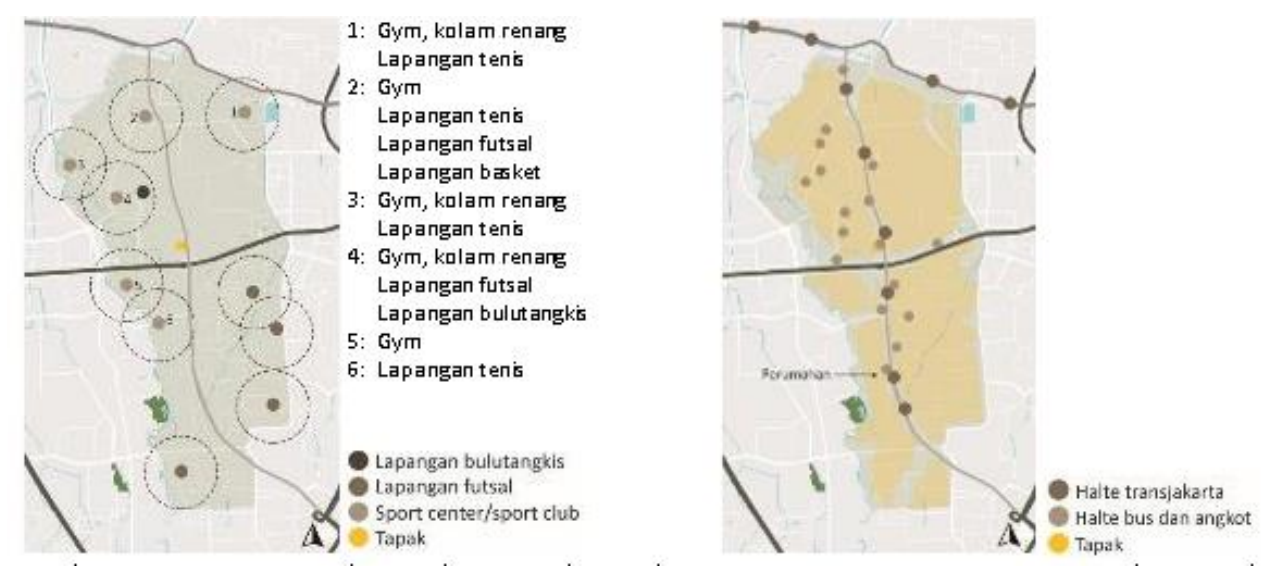

Gambar 5. Pemetaan Fasilitas Kebugaran dan Titik Transportasi Umum Kecamatan Kebon Jeruk Sumber: Google, 2019

Kehadiran fasilitas kebugaran sekitar lokasi proyek mayoritas bersifat fisik sehingga proyek menyediakan fasilitas yang bersifat fisik (dalam kapasitas secukupnya) dan juga mental/spiritual (belum hadir dalam Kecamatan Kebon Jeruk). Selain itu, radius pelayanan proyek ditetapkan sekitar $1 \mathrm{~km}$ dari posisi proyek. Persebaran titik transportasi umum sepanjang Jalan Panjang menjadikannya sebagai akses utama menuju proyek.
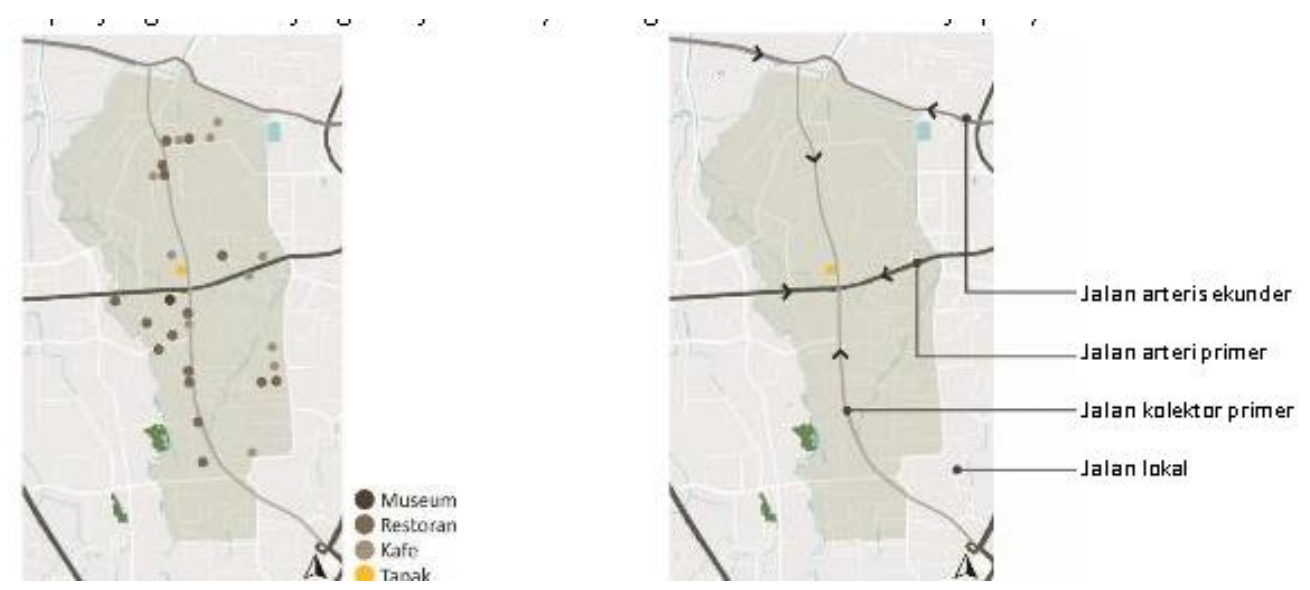

Gambar 6. Pemetaan Magnet Milenial dan Hierarki Jalan Kecamatan Kebon Jeruk Sumber: Google, 2019

Persebaran magnet milenial sepanjang Jalan Panjang menjadi peluang kunjungan generasi milenial terhadap proyek. Keberadaan Jalan Panjang (sisi timur tapak) sebagai jalan kolektor primer menjadikannya akses pengunjung serta servis menuju tapak sedangkan dari kawasan perumahan (sisi barat tapak) tidak dibuat akses secara langsung mengingat proyek yang cenderung bersifat privat. 


\section{Analisis Mezo dan Mikro}
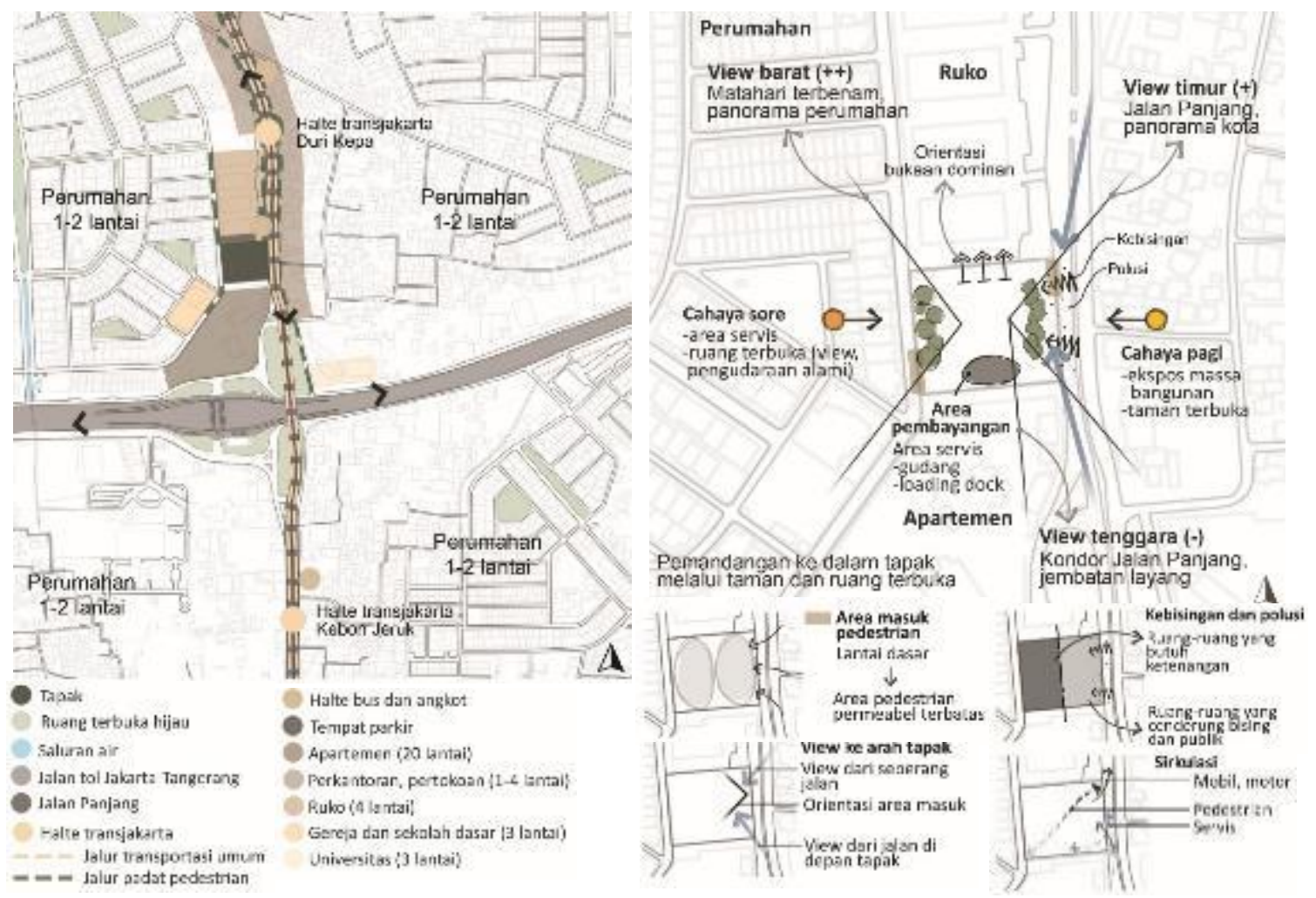

Gambar 7. Analisis Mezo (kiri) dan Analisis Mikro (kanan) Sumber: Google, 2019

Keberadaan halte transportasi umum sekitar tapak serta bangunan sekitar tapak menentukan arus pedestrian terbanyak sehingga jalur pedestrian menuju tapak dibuka dari arah timur laut tapak serta ditutup dari arah kawasan perumahan di sisi barat tapak. Tapak dibagi menjadi dua zona secara kasar dengan zona timur untuk area kegiatan yang lebih bising dan zona barat untuk area kegiatan yang tidak terlalu bising serta memerlukan ketenangan.

\section{DISKUSI DAN HASIL}

\section{Lokasi}

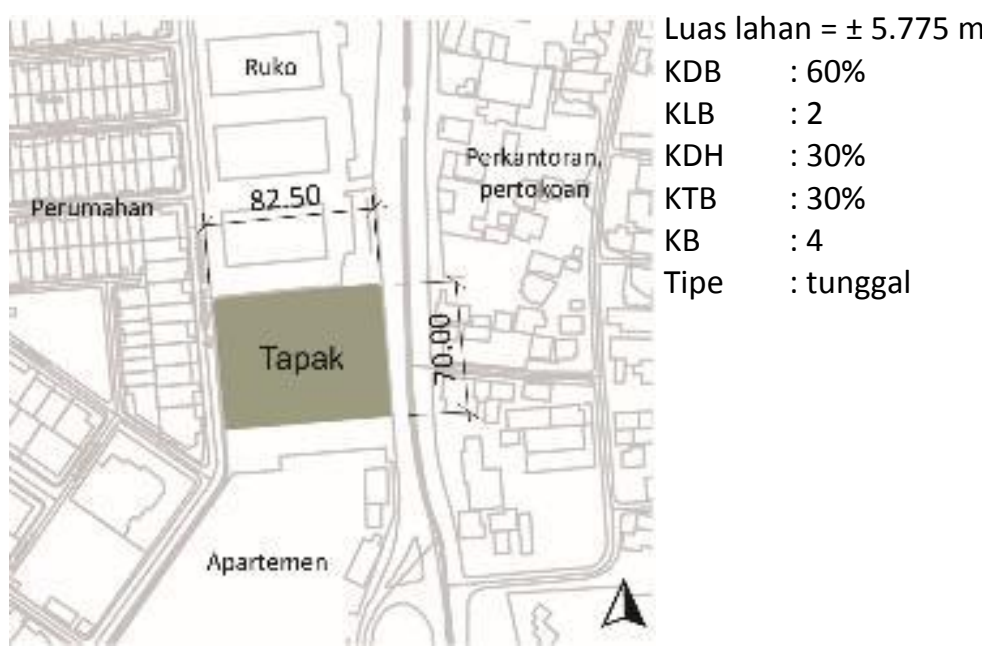

Data proyek hasil rancangan
Luas bangunan $= \pm 7.440 \mathrm{~m}^{2}$
Luas basement $= \pm 1.730 \mathrm{~m}^{2}$
Jumlah lantai $=4$ lantai
Luas lantai dasar $= \pm 3.460 \mathrm{~m}^{2}$
Luas lantai dua $= \pm 890 \mathrm{~m}^{2}$
Luas lantai tiga $= \pm 773 \mathrm{~m}^{2}$
Luas lantai empat $= \pm 437,2 \mathrm{~m}^{2}$
Luas lantai atap $= \pm 150 \mathrm{~m}^{2}$

Gambar 8. Data Tapak dan Proyek Hasil Rancangan Sumber: Google, 2019 


\section{Program Proyek Fasilitas Kesehatan Holistik}

Program yang disediakan dalam proyek fasilitas kesehatan holistik bersifat fisik dan juga mental/spiritual dengan perincian sebagai berikut.

Tabel 2. Persentase program utama bangunan

\begin{tabular}{cc}
\hline Program & Persentase dari luas bangunan \\
\hline Restoran & $9.58 \%$ \\
\hline Bar sehat & $5.58 \%$ \\
\hline Area perkebunan & $5.97 \%$ \\
\hline Seminar/workshop & $5.11 \%$ \\
\hline Pertokoan & $2.60 \%$ \\
\hline Yoga/meditasi & $11.54 \%$ \\
\hline Gym indoor & $21.76 \%$ \\
\hline Gym semi outdoor/playground & $4.88 \%$ \\
\hline Spa dan sauna & $8.37 \%$ \\
\hline Salon & $4.46 \%$ \\
\hline Area komunal & $2.32 \%$ \\
\hline Pengobatan alternatif & $3.91 \%$ \\
\hline Taman penyembuhan & $13.77 \%$ \\
\hline
\end{tabular}

Sumber: Penulis, 2019

\section{Konsep Perancangan Fasilitas Kesehatan Holistik dan Proses Gubahan Massa}

Konsep perancangan proyek ini dilatarbelakangi kondisi iklim tropis (massa bangunan dibuat tipis), alur sirkulasi yang dibuat memusat-menyebar (memperjelas alur), dan tema alam sehubungan dengan fungsi proyek yang bersangkutan dengan penyembuhan, ketenangan, dan relaksasi. Dari ketiga latar belakang tersebut, konsep yang diangkat adalah konsep sumur langit/courtyard, sehingga hasil rancangan terintegrasi dengan alam, pencahayaan dan pengudaraan alami maksimal, dan terjadi penyatuan antara ruang dalam dan ruang luar.

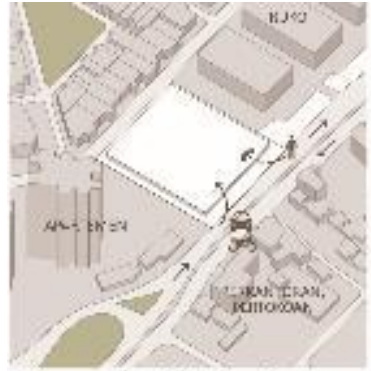

Jalur masuk sekitar tapak

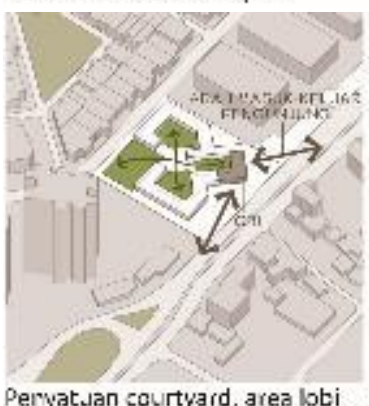

Peryatsan courtyard, area lobi

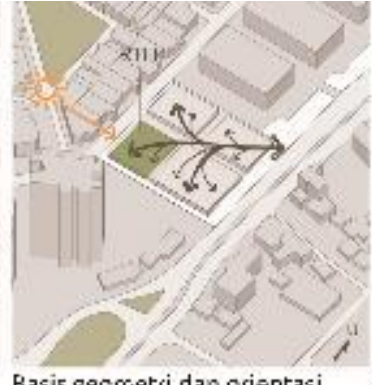

Basis gecmetri dan orientasi

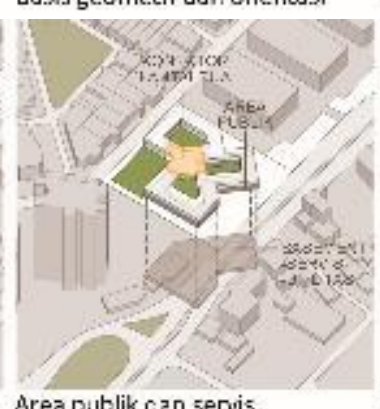

Area publik can servis

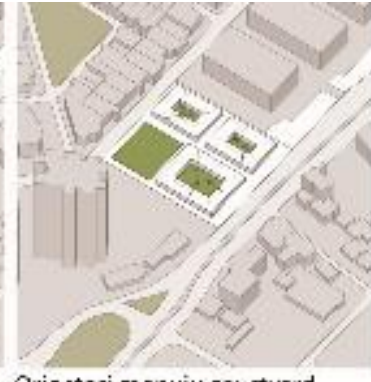

Orientasi menuju cou rtyard

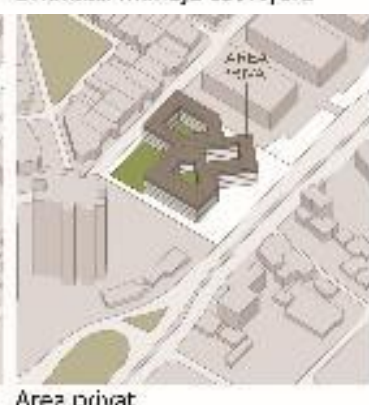

Area privat

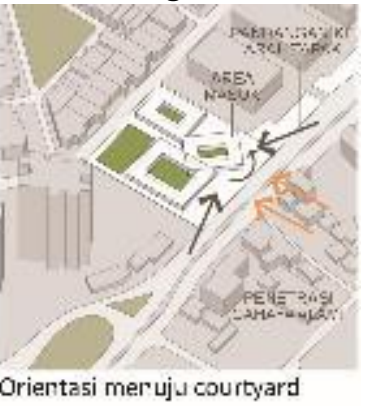

Orientasi meruju courtyard

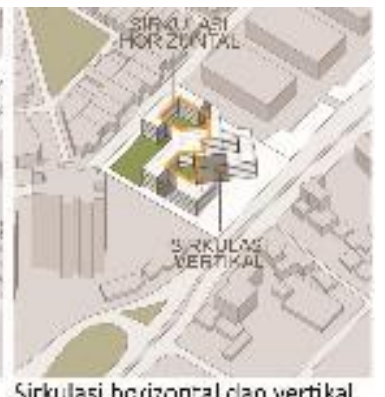

Gambar 9. Design Scheme

Sumber: Penulis, 2019 
Massa bangunan bermula dari tanggapan terhadap cahaya matahari barat serta alur sirkulasi pengunjung yang menghasilkan posisi massa serta ruang terbuka hijau pada tapak. Kemudian konsep sumur langit diintegrasikan, courtyard disatukan sekaligus disesuaikan dengan bentuk bangunan sekitar serta faktor pandangan pengunjung dari arah Jalan Panjang. Massa yang sudah terbentuk dibuat bertingkat untuk program kegiatan yang lebih bersifat privat dengan area servis ditempatkan pada lantai basement. Setelah itu sirkulasi vertikal diposisikan sesuai standar jangkauan untuk keadaan darurat, dan pada akhirnya massa direduksi agar tidak masif dan disesuaikan dengan kebutuhan program proyek.

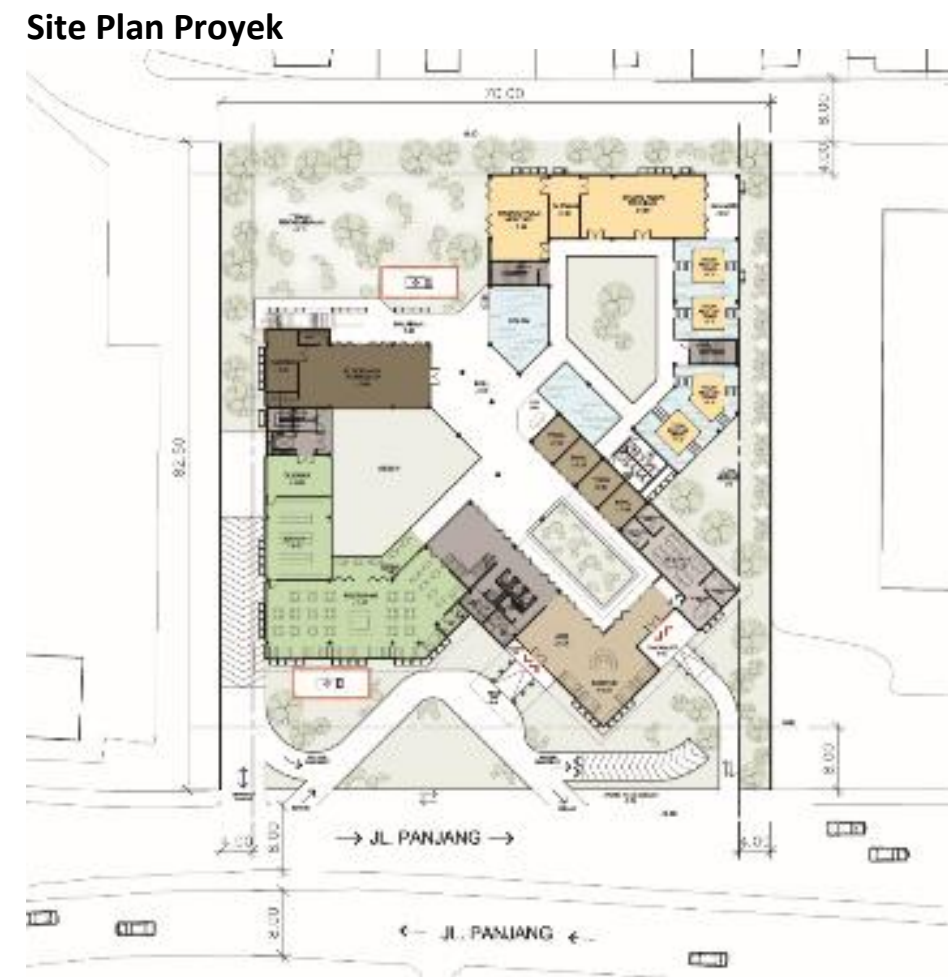

Gambar 10. Site Plan Sumber: Penulis, 2019
Keterangan :

- Sirkulasi vertikal

Area back office

Lobi

- Pertokoan

- Seminar/workshop

Restoran

Yoga/meditasi

$\checkmark$ Masuk keluar pengunjung

ฟ^ Masuk keluar servis

> Sirkulasi kendaraan pengunjung

$\rightarrow$ Sirkulasi kendaraan servis

$\rightarrow$ Sirkulasi pedestrian

एक Tempat parkir keadaan darurat (mobil pemadam kebakaran, ambulans)

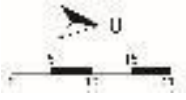




\section{Exploded Denah}

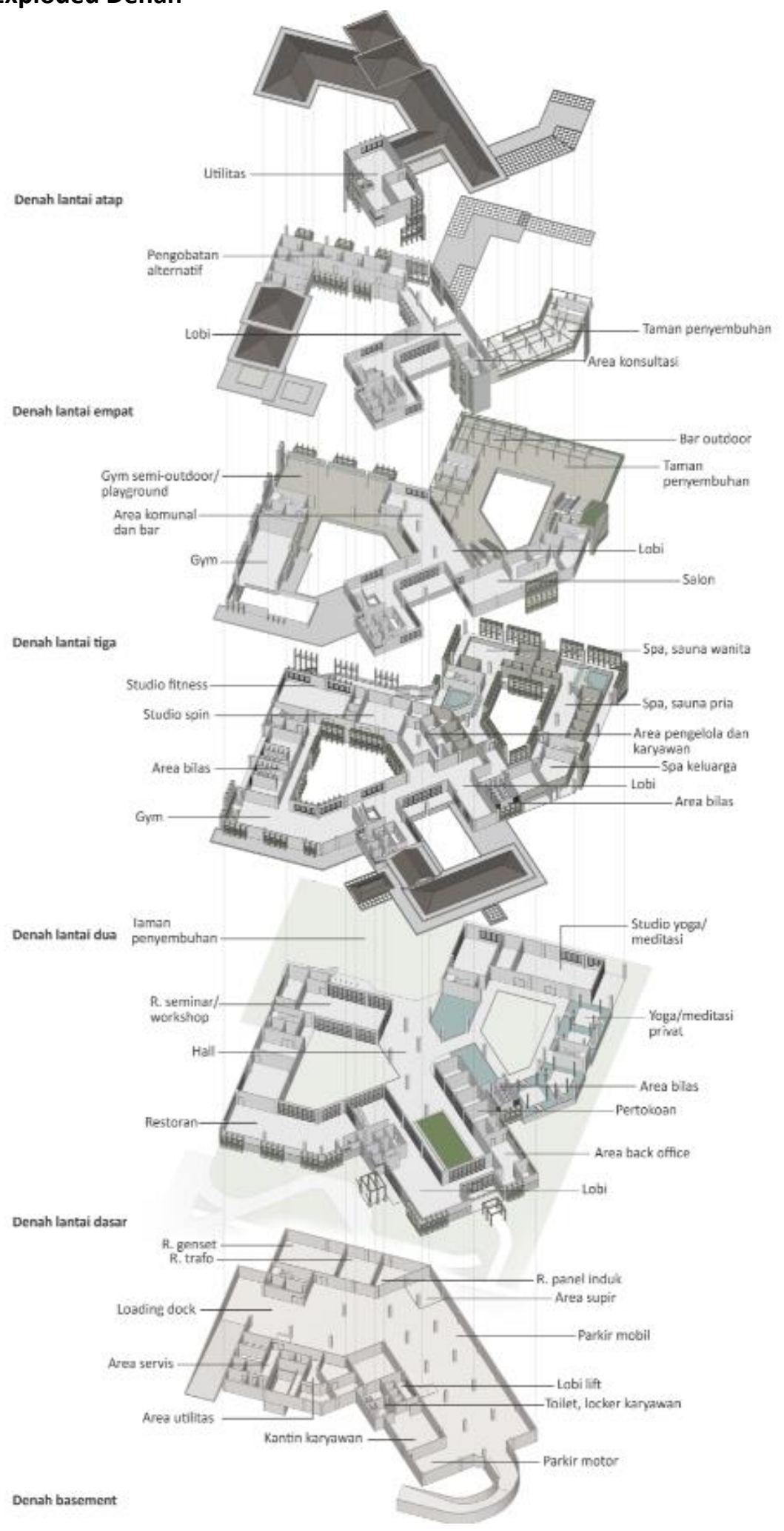

Gambar 11. Exploded Denah

Sumber: Penulis, 2019 
Denah lantai basement dikhususkan untuk area servis, utilitas (berkaitan dengan hal-hal mekanikal, elektrikal, dan plumbing), dan area parkir kendaraan pengunjung. Denah lantai dasar diisi ruang-ruang yang bersifat publik seperti area penerimaan (lobi), restoran, area perkebunan, seminar/workshop, pertokoan dan area yoga/meditasi (kebutuhan kontak dengan unsur alam). Lantai dua diisi dengan area gym, studio fitness serta spa dan sauna. Lantai tiga berisi area gym yang terkoneksi langsung dengan gym lantai dua, area gym semioutdoor, bar dan area komunal, serta taman penyembuhan. Lantai empat dikhususkan untuk area pengobatan alternatif yang bersifat privat serta taman penyembuhan yang terkoneksi pula dengan lantai di bawahnya.

\section{Tampak Bangunan}
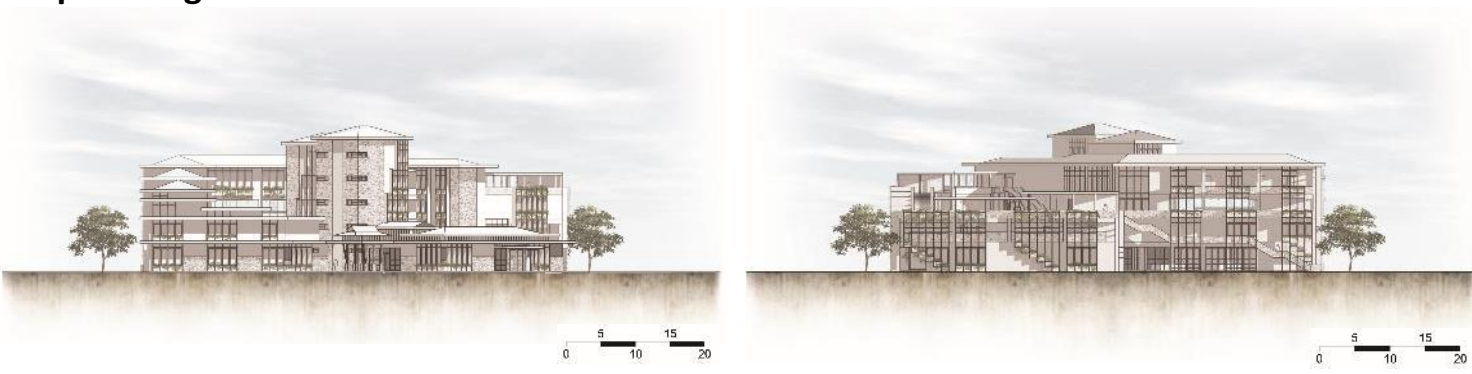

Gambar 12. Tampak Depan (Sisi Timur) dan Tampak Belakang (Sisi Barat) Sumber: Penulis, 2019

Tampak depan bangunan (menghadap Jalan Panjang, sisi timur) dibuat dengan bukaan jendela dalam jumlah yang cukup untuk memaksimalkan cahaya alami yang masuk ke dalam bangunan. Tampak belakang bangunan (menghadap kawasan perumahan, sisi barat) dibuat dengan bukaan yang minim serta fasad berkisi-kisi yang lebih banyak (menghalau sinar barat).

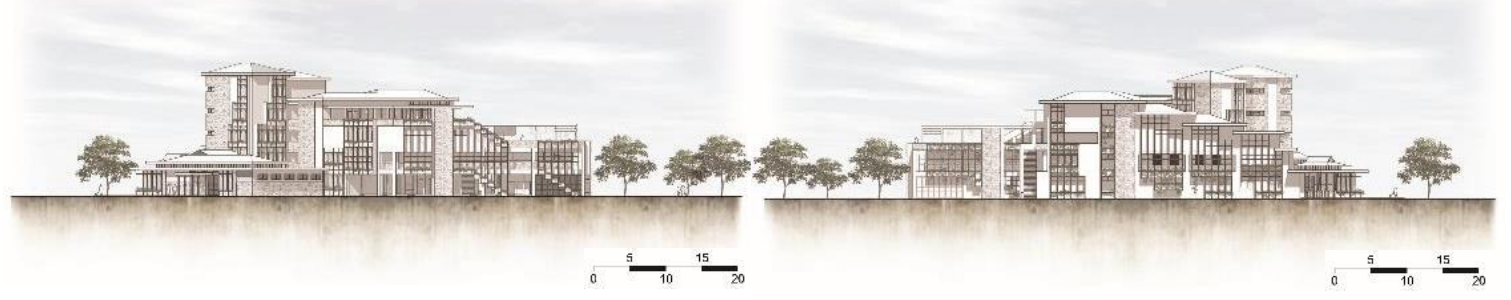

Gambar 13. Tampak Samping Kanan (Sisi Utara) dan Tampak Samping Kiri (Sisi Selatan) Sumber: Penulis, 2019

Tampak samping kanan menghadap area ruko setinggi 4 lantai sehingga dibuat dengan fasad berkisi-kisi yang padat (masalah pandangan) dan berundak agar selaras dengan siluet bangunan. Tampak samping kiri yang menghadap apartemen 20 lantai dibuat dengan bukaan yang kecil karena masalah pandangan dan meminimalkan tereksposnya area servis bangunan dari pandangan pengunjung. 


\section{Potongan Bangunan}

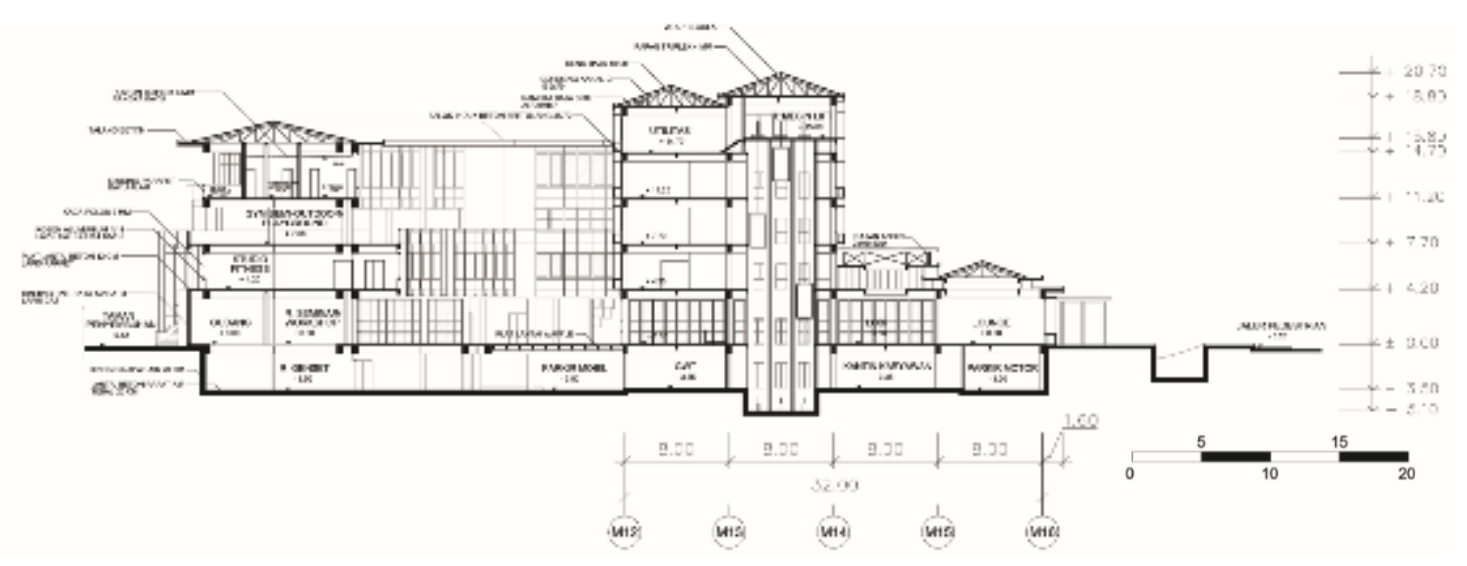

Gambar 14. Potongan A-A'

Sumber: Penulis, 2019

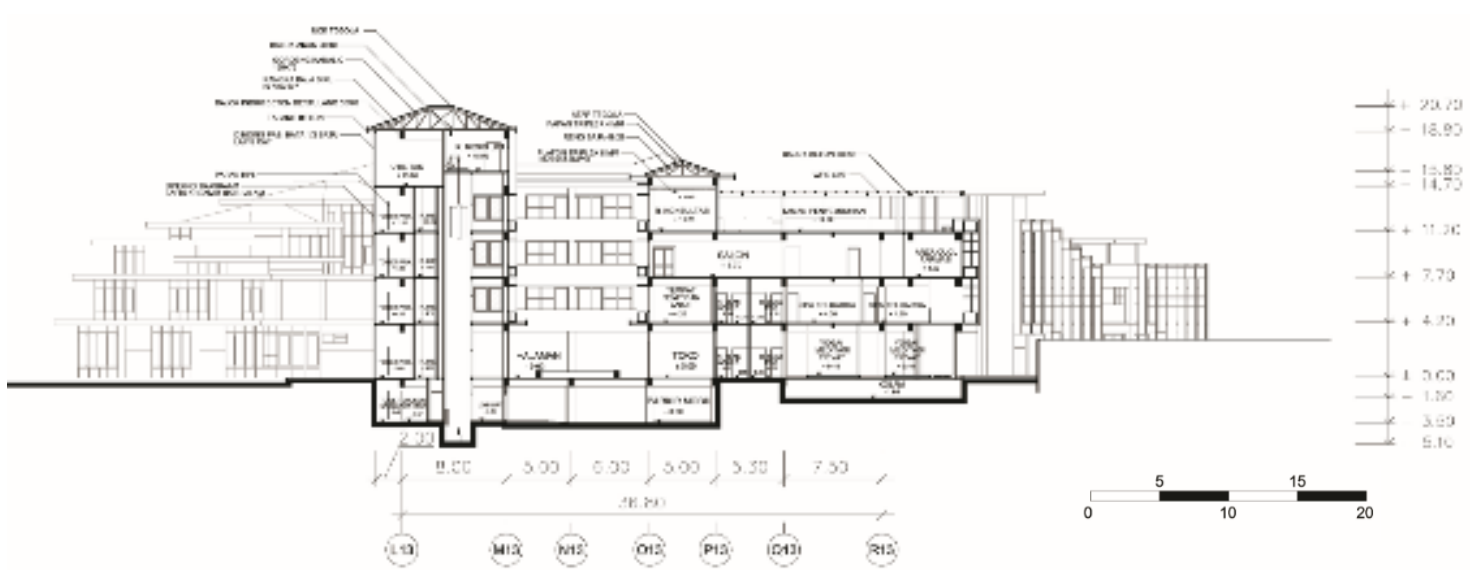

Gambar 15. Potongan C-C'

Sumber: Penulis, 2019

Bangunan menggunakan bahan beton bertulang sebagai bahan sistem konstruksinya (kolom dan balok) serta rangka atap baja siku. Fasad bangunan berbahan wood plastic composite (WCP) sehingga lebih tahan lama dan secara visual tetap terlihat alami (seperti kayu). 


\section{Perspektif Eksterior Bangunan}

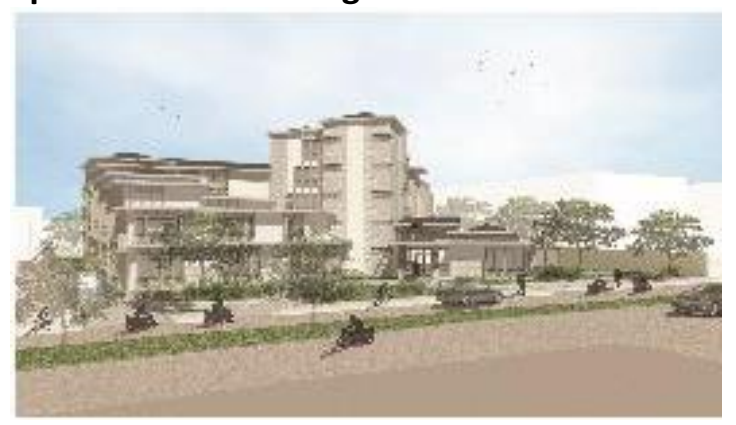

Gambar 16. Perspektif dari Sisi Tenggara Sumber: Penulis, 2019

\section{Perspektif Interior Bangunan}

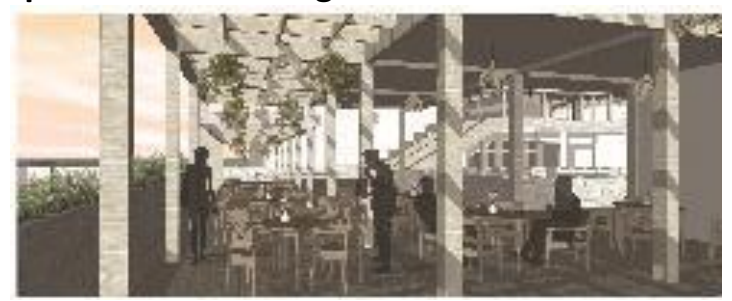

Gambar 18. Perspektif Bar Semi-outdoor Sumber: Penulis, 2019

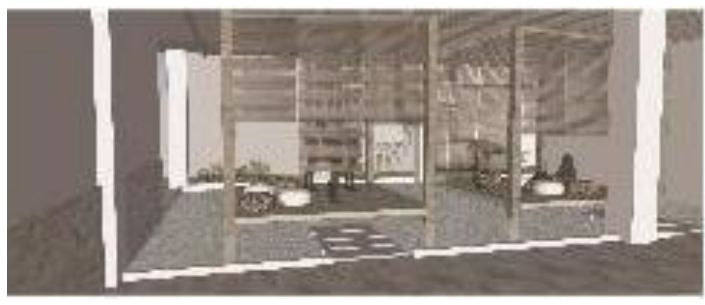

Gambar 20. Perspektif Area Yoga/Meditasi Privat Sumber: Penulis, 2019

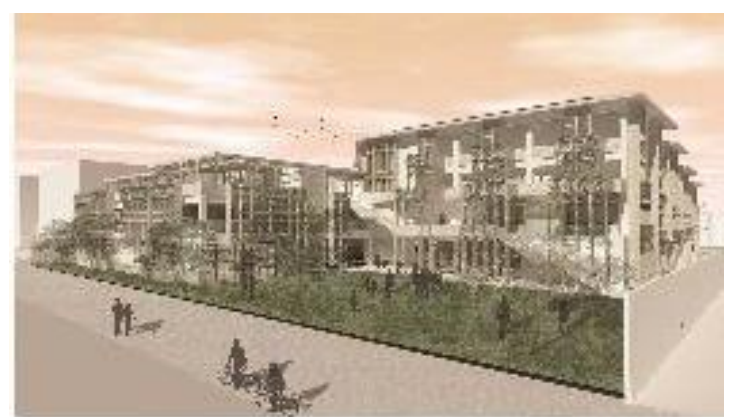

Gambar 17. Perspektif dari Area Perumahan Sumber: Penulis, 2019

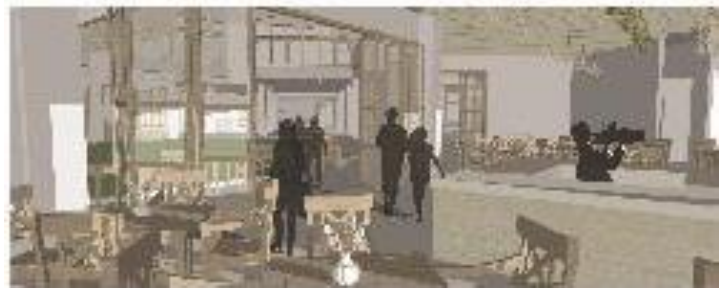

Gambar 19. Perspektif Restoran Sumber: Penulis, 2019

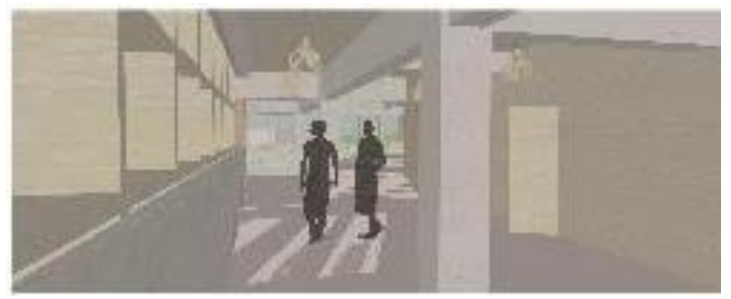

at Gambar 21. Perspektif Spa dan Sauna Pria Sumber: Penulis, 2019

\section{KESIMPULAN}

Proyek Fasilitas Kesehatan Holistik di Kebon Jeruk, Jakarta Barat diharapkan dapat memberi manfaat positif bagi lingkungan serta membantu menggerakkan pola hidup urban yang lebih sehat, seimbang, dan holistik sehingga kualitas hidup masyarakat dapat meningkat, begitu juga dengan produktivitas serta kebahagiaan. Dengan menghadirkan konsep courtyard serta tema alam, diharapkan juga frekuensi kontak antara manusia dengan alam meningkat sehingga memberi penyembuhan secara eksternal dan internal bagi pengguna bangunan. Untuk merancang proyek sejenis yang perlu diperhatikan adalah alur sirkulasi pengunjung dan bagaimana suasana ruang yang ingin ditimbulkan. Alur sirkulasi dibuat dengan jelas dan berkaitan dengan apa yang hendak ditemui pengunjung terlebih dahulu agar pengunjung merasa nyaman. Suasana ruang yang ingin ditimbulkan sebaiknya memberi unsur ketenangan dan penyembuhan dengan kehadiran unsur alam. Metode perancangan yang sebaiknya digunakan adalah metode analisis tapak secara makro hingga mikro sehingga proyek tanggap terhadap lingkungannya dan memberi dampak positif bagi lingkungan. Penulis menyarankan agar hasil rancangan bangunan sejenis lebih bersifat bersih (cleanliness) dari segi arsitektur. 


\section{REFERENSI}

Athenawellness.

(2016).

What

is

Wellness

Center?.

https://www.athenawellnesscenter.com/what-is-a-wellness-center. Februari 2019

Badan Pusat Statistik. (2019). Pengeluaran per Kapita.

https://sirusa.bps.go.id/index.php?r=indikator/view\&id=197. Januari 2019

Capra, F. (1997). Titik Balik Peradaban. Yogyakarta: Yayasan Bentang Karya

Ching, F.D.K. (1979). Bentuk, Ruang, dan Tatanan. Jakarta: Erlangga

Chopra, D. (2014). The Future of God. New York: Harmony Books

Koran Jakarta. (2017). Jakarta Barat Masih Favorit Pengembang. http://www.koranjakarta.com/jakarta-barat-masih-favorit-pengembang/. Januari 2019

Tandal, A.N., Egam, P.P. (2011). Arsitektur Berwawasan Perilaku. Media Matrasain. Vol. 8(1)

Twenge, J.M., dkk.( 2010). Generational Differences in Work Values: Leisure and Extrinsic Values Increasing, Social and Intrinsic Values Decreasing. Journal of Management. 36(5): 1117-1142 